\title{
Association between senior nursing students' perceived stress and learning environment in clinical practice
}

\author{
Hala A. Elsayes, Heba K. Obied* \\ Faculty of Nursing, Tanta University, Tanta, Egypt
}

Received: May 9, 2017

Accepted: July 21, 2017

Online Published: November 21, 2017

DOI: $10.5430 /$ jnep.v8n3p126

URL: https://doi.org/10.5430/jnep.v8n3p126

\begin{abstract}
Background and objective: Senior nursing students encounter various stressors during their practice in clinical learning environment. Inability to manage these stressors, may affect students' academic achievement and well-being, which in turn put the nursing profession at risk. This study aimed to examine the association between senior nursing students' perceived stress and learning environment in clinical practice and their coping strategies.

Methods: Study subject consisted of 400 senior nursing students enrolled in the 4th academic year at Faculty of nursing-Tanta University. Present study used descriptive design. Four tools were used to collect the data: Nursing Students' Perception of Stress in Clinical Practice, Physio-Psycho-Social Response Scale, Coping Strategies Scale, and Dundee Ready Education Environment Measure.

Results: Senior nursing students' experienced a high level of stress in clinical practice with total mean (2.87), and their response to stress indicated poor health status with total mean (2.76). Their learning environment need more effort to be improved with total mean score (2.4). There were high statistical significant positive correlation between students' perception of learning environment and their responses to stress $(p<.001)$.

Conclusions: Senior nursing students experienced high level of stress in clinical practice; their responses to stress indicated a poor health status. Majority of them used problem focused disengagement and emotional focused disengagement strategies to deal with stress in clinical practice. Their perception of learning environment indicated a more positive than negative, so learning environment need more effort to be improved. Accordingly we recommend promote healthy, supportive learning environment and refine nursing curricula.
\end{abstract}

Key Words: Senior nursing students, Stress, Response to stress, Types of stressors, Coping strategies, Clinical practice and learning environment

\section{INTRODUCTION}

Today's nursing programs adopt different strategies and pay great attention to clinical practice to supply nursing students with the required skills to assume future role as competent nurses. ${ }^{[1]}$ Although growing literature view nursing clinical practice as a stressful experience that can cause negative consequences on both students' academic performance as well as their well-being. ${ }^{[2-5]}$ Stress experienced by nursing stu- dents has profound effects on educational programs, on nurse employers, and the entire nursing profession. Stress not only jeopardize students' competencies, increase nursing shortage via increasing intention to leave the profession, but also endanger the entire quality of healthcare organizations. ${ }^{[6]}$

Stress refers to person-environment active interaction that can cause cognitive, affective as well as behavioral

*Correspondence: Heba K. Obied; Email: hebaobied@yahoo.com; Address: Faculty of Nursing, Tanta University, Tanta, Egypt. 
changes. $^{[7]}$ According to Lazarus \& Folkman (1984), ${ }^{[8]}$ psycho-social stress is person-environment relationship that is evaluated by the person as exhausting, exceeding his capabilities and hurting his well-being. Nursing students face various stressors in clinical practice including paper-work assignments, performing clinical procedures in a real life situation, shifting between different specialties as psychiatric, and community nursing, initiating therapeutic relationship as well as communicating with patients, staff and peers..$^{[3,9,10]}$ Also clinical stressors include fear of unknown, lack of knowledge and skills, and theory-practice gap. Furthermore stressors in clinical practice may arise from student-instructor negative interaction, work under instructors' observation and fear of being late and get punished. ${ }^{[7]}$ Students' stress is not limited to their studies but it might stem from a variety of sources including health condition, financial status, and romantic relationship. ${ }^{[11]}$

Nursing students' responses to stress in clinical practice vary from one person to another. Prolonged exposure to stress can cause serious harmful effects on their physical and psychological health. Physical responses include increased heart rate, headaches, gastrointestinal and sleep pattern disturbances and elevated blood pressure. Psychological responses include anxiety, withdrawal, mood swinging, panic attacks, and depression. Also they may feel being lonely, unhappy, nervous, and experiencing memory problems. Moreover stress may cause serious problems such as smoking, drug addiction, alcoholism, and suicide. Students' stress can be viewed academically in their inability to finish their assignments on time, inability to solve problems, deterioration in their grades. ${ }^{[7,12,13]}$

Nursing students' behaviors to cope with stress are influenced by the degree, duration, and frequency of stressful events experienced in the learning environment. Stress coping process is the complex response taken by the student in an attempt to eliminate stress from the environment that exceed his capabilities. Hence, coping cannot be viewed as one-time action; but rather, set of responses, happen over time, by which the student regain his stability during stressful situations. ${ }^{[14]}$ Coping strategies can be described as positive or negative and as active or reactive. Active strategies that deal with actual stressful situations while, reactive strategies mean dealing with the individual's own thoughts and feelings. ${ }^{[15,16]}$

Lazarus and Folkman (1984) ${ }^{[8]}$ specified two types of stress coping strategies problem-focused and emotion-focused. Problem focused strategy encompass thoughts, behaviors, and approaches directed to eliminate or decrease the stressful situation, occur once the student trust his ability to change the situation, thus he decide the best strategy and putting it into action. Emotion-focused strategy encompass thoughts, behaviors, and approaches directed to control and decrease stressful emotions associated with a stressful situation, occur once the student realize that he has to tolerate the stressor to diminish his suffering, because the situation is beyond his ability to change it. These two strategies can be used by the students to respond to stressful situations. ${ }^{[17]}$

Afterwards Tobin (1985) ${ }^{[18]}$ distinguished two coping strategies engagement that reflects the student attempt to engage in efforts to manage stressful situations by engaging in active ongoing negotiation with stressful situation (positive). The engagement strategy includes problem-focused engagement and emotion-focused engagement strategies. While, disengagement reflects the student give-up and is unable to interact with stressful situation, he avoid thinking about the situation, refuse to share his feelings with others and begin to blame and criticize himself (negative). The disengagement strategy includes problem-focused disengagement and emotion-focused disengagement strategies.

Clinical learning environment where nursing students are being prepared to be future professional nurses play an important role in their academic achievement and success, however it can result in serious additional burden that lead to students' anxiety and stress. Learning environment has been defined as everything that is happening in the classroom or clinical setting. Learning environment is a combination of physical settings, backgrounds, and cultures that form the nature of students' interactions and behaviors, and how teachers organize the educational setting to facilitate learning process. Assessing students' perception of the learning environment is very crucial to facilitate implementation of required modifications and thus optimizing the educational environment that enhance students' learning experiences and outcomes. ${ }^{[19-21]}$

Nursing students cannot avoid learning related stressors; hence their ability to cope with these stressors is pivotal to ensure their academic success. ${ }^{[16]}$ Consequently the undergraduate stage is considered critical period need to be carefully and scientifically managed by nursing schools' administration as well as the academic staff to ensure the quality of their graduates and help them to cope effectively with those stressors. Little is known about clinical practice stress experienced by senior nursing students at Tanta University and their coping strategies as well as the effect of learning environment on their perception of stress. Therefore, the current study intended to assess the effect of learning environment on senior nursing students' perceived stress and their coping strategies during clinical practice. Providing this data base about senior nursing students is crucial to detect 
the gaps whether it is related to the teachers, students, or the atmosphere to take the required steps to enhance their academic advancement.

\subsection{Aim of the study}

Our study aimed to examine the association between senior nursing students' perceived stress and learning environment in clinical practice and their coping strategies.

\subsection{Research questions}

(1) What are the major sources of stress in clinical practice for senior nursing students?

(2) What are the senior nursing students' responses to stress in clinical practice?

(3) What are the stress coping strategies used by senior nursing students?

(4) Is there an association between senior nursing students' perceived stress and learning environment in clinical practice?

\section{MATERials AND METHOD}

\subsection{Design}

Descriptive cross-sectional design was used to carry out the present study.

\subsection{Setting}

This study was conducted at Faculty of nursing-Tanta University.

\subsection{Subject}

A total of 400 senior nursing students enrolled in the 4 th academic year and were willing to participate in the current study.

\subsection{Tools for data collection}

Four self-administered questionnaires were used to collect the data.

Tool I: Nursing Students' Perception of Stress in Clinical Practice Questionnaire. It was developed by Sheu et al. $(2002)^{[9]}$ to assess types of stressors and stress levels. It included two parts; Part one: encompassed students' personal data including gender, age, income, marital status, residency, home-faculty distance, nursing course currently enrolled in, hours of studying and hours of sleeping per day. Part two: Perceived Stress Scale, included six subscales lack of professional knowledge and skills ( 3 items), stress from assignments and workload (5 items), stress from taking care of patients ( 8 items), stress from clinical environment (3 items), stress from teachers and nursing staff (6 items) and stress from peers and daily life (4 items). Based on the total score of the six subscales the stress levels were specified as high ranged between 2.67-4.00, moderate ranged between 1.34-2.66, and low ranged between 0-1.33.

Tool II: Physio-Psycho-Social Response Scale, developed by Sheu et al. (2002) ${ }^{[9]}$ to assess responses to stress, it included three subscales emotional ( 7 items), social behavioral (6 items) and physical symptoms (8 items). Students' responses to stress classified as best health ranged between 0-1.33, good health ranged between 1.34-2.66, and poor health ranged between 2.67-4.00. Scoring system, used 5 points Likert scale ranged from Never $=0$ to Always $=4$

Tool III: Coping Strategies Scale, developed by Tobin $(1985),{ }^{[18]}$ it was divided into eight subscales (primary subscale) problem solving (9 items), cognitive restructuring (9 items), express emotions ( 9 items), social support (9 items), problem avoidance ( 9 items), wishful thinking (9 items), self criticism (9 items) and social withdrawal (9 items). Scoring system used 5 points Likert scale ranged from Never $=0$ to Always $=4$. Secondary subscale, including problem focused engagement is the sum of problem solving and cognitive restructuring subscales. Emotional focused engagement is the sum of social support and express emotions subscales. Problem focused disengagement is the sum of problem avoidance and wishful thinking subscales. Emotional focused disengagement is the sum of social withdrawal and self criticism subscales. Tertiary subscale, included engagement is the sum of problem focused engagement and emotional focused engagement subscales, and disengagement is the sum of problem focused disengagement and emotional focused disengagement.

Tool IV: Dundee Ready Education Environment Measure, it was developed by McAleer \& Roff $(2001)^{[22]}$ to assess the educational climate. It included students' perception of learning (12 items), students' perception of teachers (11 items), students' academic self-perception (8 items), students' perception of atmosphere (12 items), and students' social selfperception (7 items). Scoring system used 5 points Likert Scale ranged from rarely $=0$ to always $=4$. The total senior nursing students' perception of learning environment were categorized as very poor from 0 up to 50 , plenty of problems between 51 and 100, more positive than negative ranged between 101-150, and 151-200 indicated excellent learning environment. Students' perception of learning subscale score indicated 0-12 very poor, 13-24 teaching is viewed negatively, 25-36 a more positive approach, and 37-48 teaching highly thought of. Students' academic self-perceptions subscale score indicated 0-8 feeling of total failure, 9-16 many negative aspects, 17-24 feeling more on the positive side, and 25-32 confident. Students' social self-perceptions subscale 
score indicated 0-7 miserable, 8-14 not a nice place, 15-21 not too bad, and 22-28 very good socially. Students' perception of atmosphere subscale score indicated 0-12 a terrible environment, 13-24 many issues need changing, 25-36 more positive atmosphere, and 37-48 good feeling overall. Students' perception of teachers subscale score indicated 0-11 abysmal, 12-22 in need of some retraining, 23-33 moving in the right direction, and 34-44 model teachers.

\subsection{Ethical considerations}

Researchers obtained an official permission from Dean of Faculty of Nursing-Tanta University to carry out the study. The purpose of the study was clarified to the senior nursing students, then their consents were obtained, and they were informed about their right to withdraw and the confidentially of their data. The students were reassured that their participation will not affect their grades.

\subsection{Validity and reliability}

Prior data collection, a pilot study was conducted to check the clarity of the study tools on (10\%) of senior nursing students (excluded from the study sample). Crombach alpha coefficient was used to check tools reliability, for tool I, II, and III $(0.85,0.80$, and 0.92$)$ respectively. The content validity of the study tools (after translation in to Arabic language) was checked by five experts in the field of nursing administration, and psychiatric nursing, based on the experts' opinions and pilot study; the tools were modified. The content validity index of the study tool I, II, and III were $94 \%, 90 \%$, and $88 \%$ respectively.

\subsection{Field work}

Researchers met the participant senior nursing students in small groups during the second semester expanded from February up to June. They fill in the study tools in the presence of the researchers. Each researcher collected the data from students of the opposite specialty (to eliminate the Hawthorne effect).

\subsection{Statistical analysis}

The data was collected, tabulated and statistical analysis were done using SPSS 19.0 statistical software package. For quantitative data the mean and standard deviation were used. For qualitative data number and percent distribution was calculated. Spearman's rho was used to find Correlation Coefficient at $p$-value $<.05$.

\section{Results}

Table 1 illustrates personal characteristics of participant senior nursing students. The highest percent of the participant nursing students (66\%) aged between 21-23 years and majority of them $(81.2 \%)$ were female. Majority $(84.8 \%)$ of the nursing students' family income was sufficient, high percent $(70.5 \%)$ of them lived in villages. Equal percent $(50 \%$ and $50 \%)$ were enrolled in community nursing and psychiatric nursing courses respectively. Around two thirds (75\%) of the nursing students were single. Around half of them (47.8\%) home-faculty distance take between 30-60 mints. More than half $(53.3 \%)$ of the nursing students study less than 2 hours/ day and $(29 \%)$ of them sleep less than 5 hours/day.

Table 1. Personal characteristics of participants nursing students $(n=400)$

\begin{tabular}{llll}
\hline Items & No. (\%) & Items & No. (\%) \\
\hline Age (years) & & Studying hours/day & $213(53.3)$ \\
$<21$ & $130(32.5)$ & $<2$ & $139(34.8)$ \\
$21-23$ & $264(66)$ & $2-3$ & $39(9.8)$ \\
$>23$ & $6(1.5)$ & $4-5$ & $9(2.3)$ \\
Gender & & $>5$ & $57(14.4)$ \\
Male & $75(18.8)$ & Home-faculty distance & $191(47.8)$ \\
Female & $325(81.2)$ & $<30$ mins & $61(15.3)$ \\
Family income & & $30-60$ mins & $91(22.8)$ \\
Sufficient & $339(84.8)$ & $>60-120$ mins & $118(29.5)$ \\
Insufficient & $61(15.2)$ & $>120-180$ mins & $282(70.5)$ \\
Sleeping hours/day & & Place of residency & \\
$<5$ & $116(29)$ & City & Village \\
$5-6$ & $95(23.8)$ & & $300(75)$ \\
$7-8$ & $99(24.8)$ & Marital status & $100(25)$ \\
$>9$ & $90(22.5)$ & Single & Married \\
Nursing course currently enrolled in & & & \\
Community & $200(50)$ & $200(50)$ &
\end{tabular}


Figure 1 illustrates types of stressors in clinical practice perceived by participant senior nursing students. The total perceived stress mean was 2.87 which indicated that participant nursing students experienced a high level of stress in clinical practice. The participant nursing students' highest three stressors means were 3.07, 3, and 2.97 regarding assignment \& work load, teachers \& nursing staff and peer \& daily life respectively that shows high levels of stress. While, the lowest stressor mean was 2.58 regarding lack of knowledge $\&$ skills that indicate a moderate level of stress.

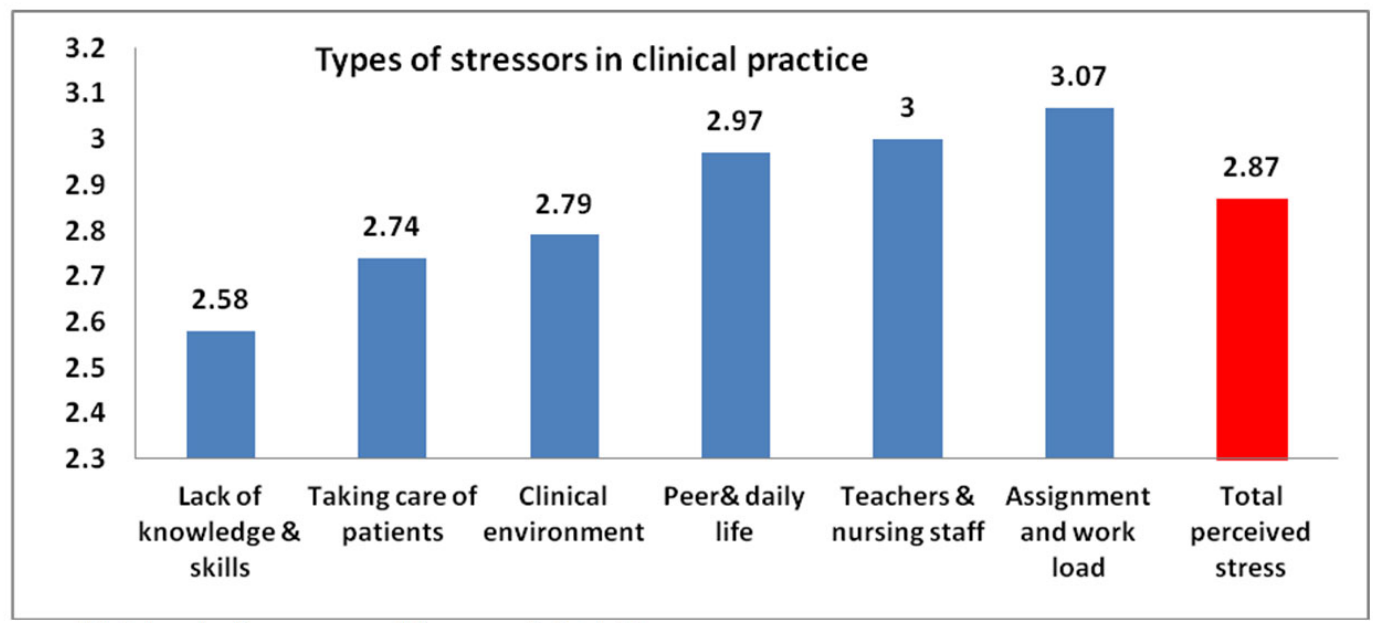

- High level of stress ranged between 2.67-4.00

- Moderate level of stress ranged between 1.34-2.66

- Low level of stress ranged between 0-1.33

Figure 1. Types of stressors in clinical practice perceived by participant senior nursing students

Figure 2 represents participant senior nursing students' re- The senior nursing students' had $(2.84,2.79$, and 2.68$)$ mean sponses to stress in clinical practice. The mean of total response to stress experienced by participant nursing students scores regarding emotional, social and physical symptoms in clinical practice was 2.76 that indicate poor health status. of stress respectively that indicate poor health status.

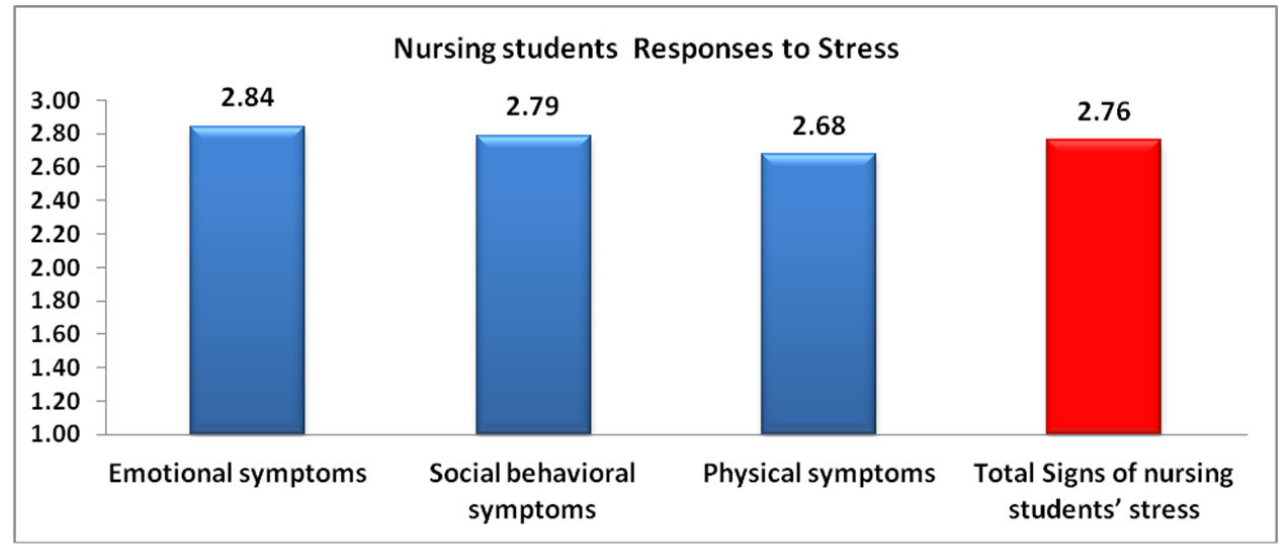

- Best health status ranged between 0-1.33

- Good health status ranged between 1.34-2.66

- Poor health status ranged between 2.67-4.00

Figure 2. Participant senior nursing students' responses to stress in clinical practice

Figure 3 shows primary scale coping strategies used by participant senior nursing students to deal with stress in clinical practice. Figure 3 shows that around three quarters of the participant senior nursing students $(79 \%, 76 \%, 75 \%$, and $74 \%)$ sometimes and always use wishful thinking, self criticism, social withdrawal, and problem avoidance coping strategies respectively to deal with stress in clinical practice. 


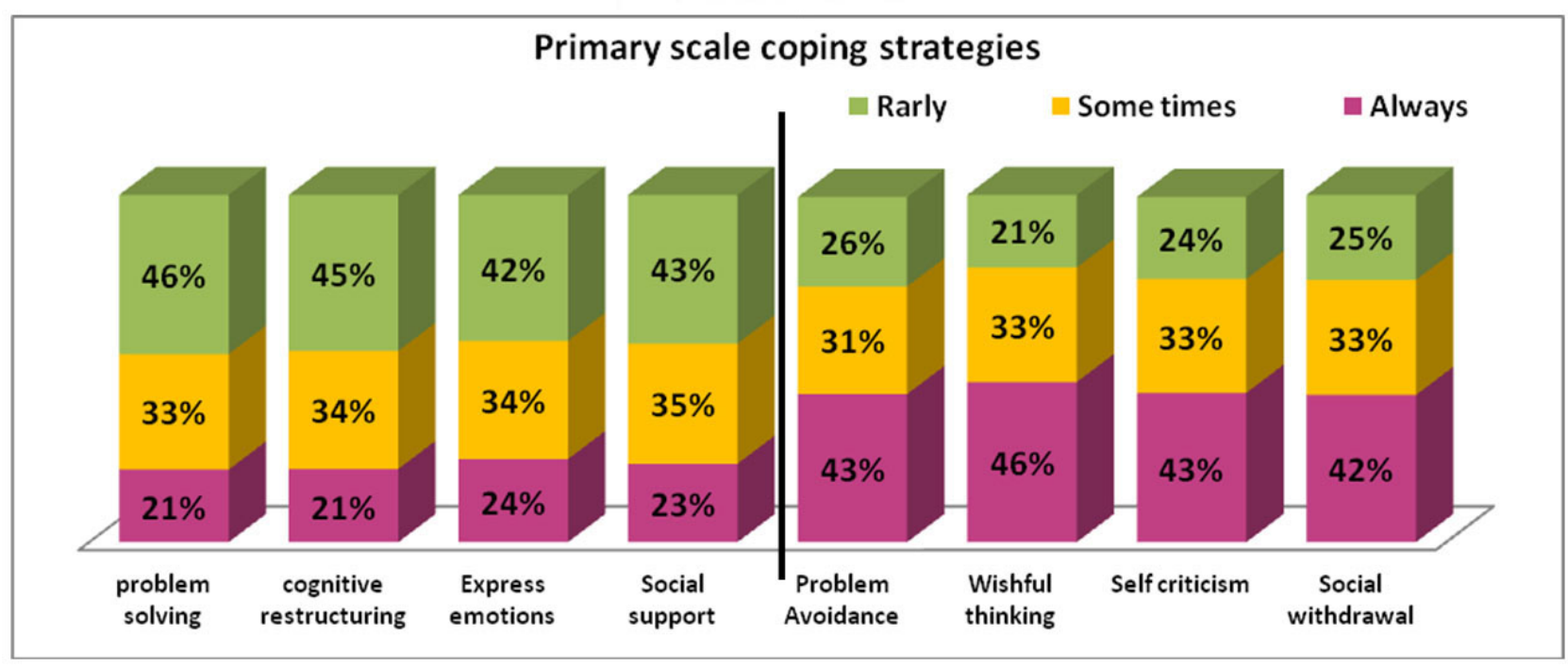

Figure 3. Primary scale coping strategies used by senior nursing students to deal with stress in clinical practice

Figure 4 illustrates coping strategies secondary scale used by senior nursing students to deal with stress in clinical practice. Around three quarters of the participant senior nursing students $(77 \%$ and $76 \%)$ sometimes and always use problem focused disengagement and emotional focused disengagement strategies respectively to deal with stress in clinical practice.

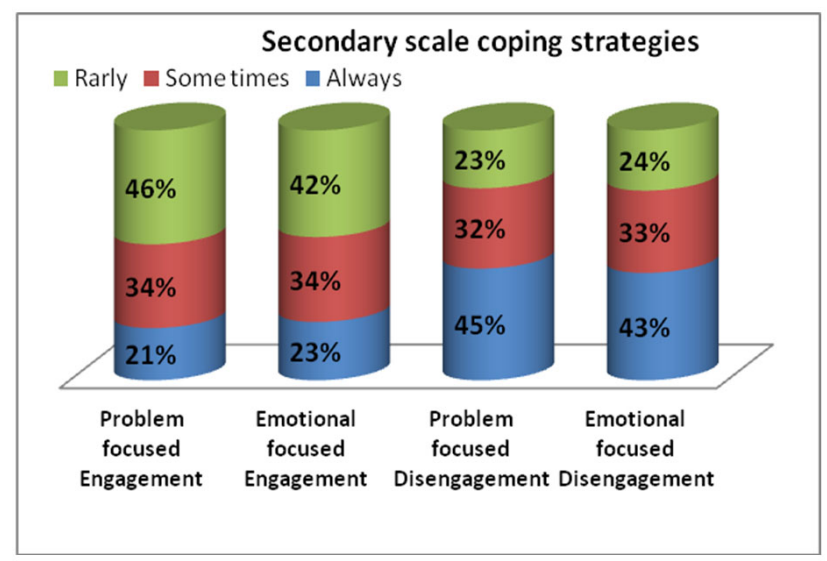

Figure 4. Coping strategies secondary scale used by senior nursing students to deal with stress in clinical practice

Figure 5 represents coping strategies tertiary scale used by senior nursing students to deal with stress in clinical practice. Around three quarters of the participant senior nursing students (77\% and $76 \%$ ) sometimes and always use problem focused disengagement and emotional focused disengagement strategies respectively to deal with stress in clinical practice.

Figure 6 shows senior nursing students' perception meanscores of learning environment. The total mean score of Published by Sciedu Press senior nursing students' perception regarding learning environment was 2.4 that point out a learning environment that need more effort to be improved. The figure shows that the highest mean score were 2.8 and 2.4 regarding students' perception of learning and students' academic self-perceptions respectively. While the lowest mean were 2.1 and 2.2 regarding student perception of teachers and student perception of atmosphere respectively.

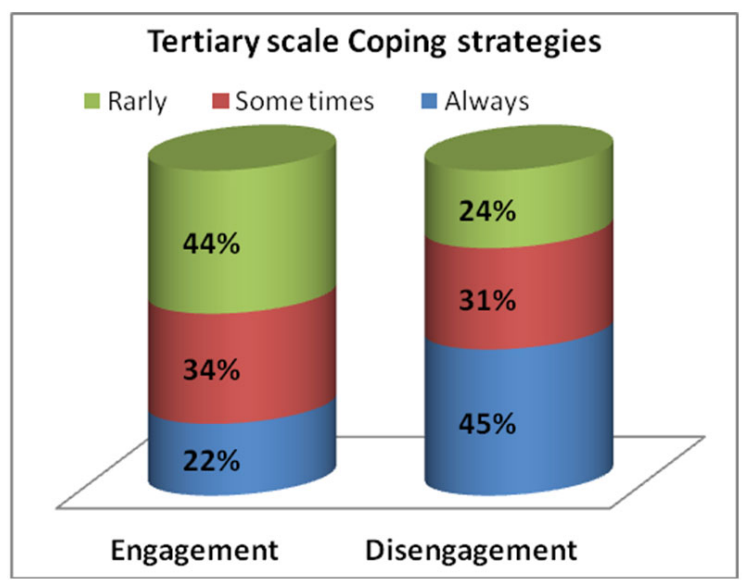

Figure 5. Coping strategies tertiary scale used by senior nursing students to deal with stress in clinical practice

Table 2 illustrates senior nursing students' scores of Dundee Ready Education Environment Measure (DREEM). The overall senior nursing students DREEM score was found to be $118 / 200$ that represent a more positive than negative. The students' perception of learning was 34 that signify a more positive approach, while their perception regarding teachers was 22 that indicate teachers need some retraining. 


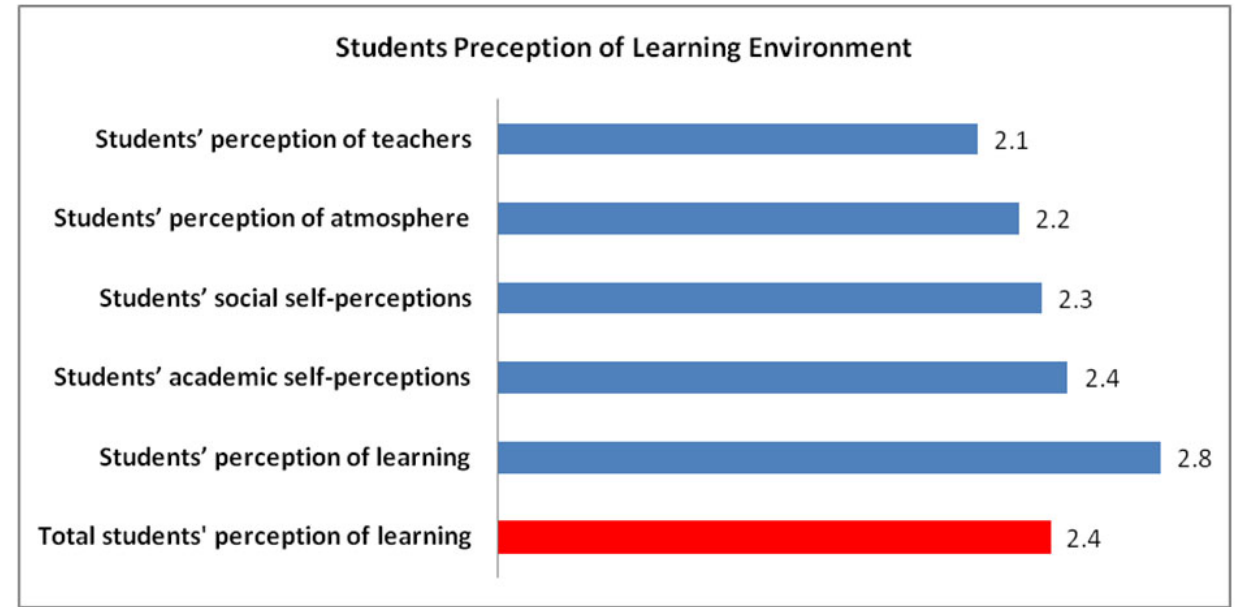

- $3.5 \leq$ mean score indicate positive learning environment.

- 2 up to 3 mean score indicate learning environment that could be improved.

- $2>$ mean score indicate problematic area in the learning environment.

Figure 6. Senior Nursing Students' perception mean-scores of learning environment

Table 2. Senior Nursing Students' scores of Dundee Ready Education Environment Measure (DREEM)

\begin{tabular}{ll}
\hline $\begin{array}{l}\text { (DREEM) subscales and its } \\
\text { indication }\end{array}$ & $\begin{array}{l}\text { Senior nursing students' } \\
\text { DREEM Score/200 }\end{array}$ \\
\hline Total DREEM score & 118 \\
Students' perception of learning & 34 \\
Students' academic self-perceptions & 19 \\
Students' social self-perceptions & 17 \\
Students' perception of atmosphere & 26 \\
Students' perception of teachers & 22 \\
\hline
\end{tabular}

Table 3 illustrates correlation between senior nursing students' perception of learning environment and types of stressors, responses to stress and coping strategies. The table shows that there were a high statistical significant correlation between senior nursing students' perception of learning environment and their responses to stress, also there were a high statistical significant negative correlation between their perception of learning environment and their coping strategies at $p<.001$.

Table 4 shows comparison between nursing students' perception of stress, responses to stress, coping strategies, and perception of learning environment according to nursing course currently enrolled in. There were a statistical high significant difference between students enrolled in community course and students enrolled in psychiatric nursing and nursing administration courses total responses to stress and total perception of learning environment at $p<.01$.

Table 3. Correlation between senior nursing students' perception of learning environment and types stressors, responses to stress and coping strategies

\begin{tabular}{lllll}
\hline Main scales & & Types of stressors & Response to stress & Coping strategies \\
\hline Perceived learning environment & Spearman's rho & .235 & .475 & -.145 \\
(DREEM) & $p$ value & .099 & $.000^{* *}$ & $.001^{* *}$ \\
\hline
\end{tabular}

Table 4. Comparison between nursing students' perception of stress, responses to stress, coping strategies, and perception of learning environment according to nursing course currently enrolled in

\begin{tabular}{|c|c|c|c|}
\hline \multirow[t]{2}{*}{ Main scales } & Community nursing Group & $\begin{array}{l}\text { Psychiatric nursing\& nursing } \\
\text { administration Group }\end{array}$ & \multirow[t]{2}{*}{$t$ (p-value) } \\
\hline & Mean \pm SD & Mean \pm SD & \\
\hline Types of stressors & $2.90 \pm 0.69$ & $2.44 \pm 0.57$ & $1.00(.3192)$ \\
\hline Responses to stress & $2.93 \pm 0.82$ & $2.23 \pm 0.69$ & $4.35(.0000)^{* *}$ \\
\hline Coping strategies & $3.32 \pm 0.78$ & $3.22 \pm 0.61$ & $1.34(.1821)$ \\
\hline Perceived learning environment (DREEM) & $3.14 \pm 0.28$ & $3.36 \pm 0.29$ & $-7.73(.0000)^{* *}$ \\
\hline
\end{tabular}

$* * p<.001$ 


\section{Discussion}

The participant senior nursing students experienced a high level of stress in clinical practice. The highest three stressors in our clinical environment as perceived by senior nursing students were regarding assignment \& work load, teachers $\&$ nursing staff and peer $\&$ daily life. They also experienced moderate level of stress regarding lack of knowledge and skills. This may be due to our senior nursing students have to pass three major nursing courses including nursing administration, community nursing, and psychiatric nursing which in turn means those nurses have to spend about twenty clinical hours/week, and they had many assignments, projects and exams in addition to other subjects. Also those students experience peer competition to get high scores to improve their post graduate chances for being recruited in either academic or eminent healthcare organizations. Furthermore we did not apply credit hours system so students experience inflexible timetable and their individual differences is not considered.

Regarding the level of stress experienced by nursing students in clinical practice, our study results are in keeping with the findings obtained by earlier authors such as Hassanein et al. (2017), ${ }^{[17]}$ Eswi (2013), ${ }^{[23]}$ Labrague (2013) ${ }^{[7]}$ and Chan (2009) ${ }^{[24]}$ Seyedfatemi (2007), ${ }^{[25]}$ and Tully $(2004)^{[26]}$ they found that nursing students showed high and moderate stress levels. On the other hand, Papazisis et al. (2008) ${ }^{[27]}$ found that Greek nursing students demonstrated mild levels of stress.

Concerning the type of stressors experienced by nursing students in clinical practice Labrague (2013), ${ }^{[7]}$ Wang \& Yeh $(2005)^{[28]}$ and Evans \& Kelly (2004) ${ }^{[29]}$ found that most common sources of stress included, unfamiliarity with clinical environment, gap between theory and practice, and lack of professional knowledge and skills. Also Mohamed \& Abd El-Hafez (2015) ${ }^{[12]}$ and Khater et al. (2014) $)^{[15]}$ found that patient acuity level, elevated workload and, assignments, fear of committing mistakes, divergence between the ideal well supported lab experience and real clinical practice, and examinations were sources of stress for nursing students.

According to senior nursing students' responses to stress in clinical practice our results indicated they experienced poor health status (Physio-Psycho-Social). They feel giddy, vertigo, nervous, and miserable. This informs us that our nursing students were unable to cope with different stressors faced during clinical practice. Contradicting to our study findings Labrague (2013), ${ }^{[7]}$ Sheu, 2002, ${ }^{[9]}$ and Chan (2009), ${ }^{[24]}$ found that the perceived physio-psycho-social health indicated that their nursing students had good health.

Concerning coping strategies to deal with stress in clinical practice our study results revealed that majority of participant

Published by Sciedu Press senior nursing students sometimes and always used wishful thinking, self criticism, social withdrawal, and problem avoidance. This elucidated that our senior nursing students used both problem and emotional focused disengagement coping strategies to deal with stress in clinical practice. Our nursing students were unable to manage their academic tasks and clinical stress effectively. Scientifically, the persons' ability to cope with stress based on multiple factors including age, past experience, gender, residency, family composition, health condition, and even the season and time, thus there is no ideal way to deal with stress WHO/EHA (1999). ${ }^{[30]}$ But equipping our students with the appropriate strategies to deal with stress can help them to pass their educational period smoothly and enjoy their time.

The most commonly used coping strategies for Hassanein et al. (2017) ${ }^{[17]}$ were problem-focused coping, seeking social support, detachment, wishful thinking, and focusing on the positive, and for Kumar (2011) ${ }^{[31]}$ were seeking diversion, solving problems, and developing social support. While Sohail $(2013)^{[32]}$ and Wang \& Yeh (2005), ${ }^{[28]}$ they found that nursing students use combination of problem and emotionfocused coping strategies. While Chan (2009), ${ }^{[24]}$ and Pryjmachukl \& Richards (2007) ${ }^{[33]}$ found that nursing students employed emotion-focused strategies when facing stress in clinical practice. On the other hand Shaban $(2012)^{[34]}$ and $\mathrm{Ni}(2012)^{[35]}$ revealed that majority of their study sample applied problem-focused strategies to deal with stressful situations. Contradicting to our study results AL-Zayyat and Al-Gamal (2014) ${ }^{[16]}$ Karimollahi (2011) ${ }^{[36]}$ concluded that nursing students utilized different negative strategies to deal with stress in psychiatric course such as avoiding difficulties during clinical practice, waiting others to solve the problem, losing temper, and having eating disorders and taking a long sleep.

The total mean score of our senior nursing students' perception regarding learning environment pointed out that our learning environment need more effort to be improved. The highest mean score were regarding students' perception of learning and students' academic self-perceptions. While the lowest mean were regarding student perception of teachers and student perception of atmosphere that indicate our teachers need some retraining and atmosphere required to be reconsidered. This may be due to several causes including inappropriate teacher /student ratio (1/30) in clinical setting which may lead to unfair evaluation, and lack of guidance, in addition to lack of teachers' experience as the clinical courses mostly given by instructors and assistant lecturers. Thus clinical teaching staff may be more authoritarian and inflexible as they are fresh and overloaded with students' assignments as well as their own postgraduate studies and 
their personal life. Moreover, senior nursing students need to feel calm and comfort to their teacher, not to be afraid of asking questions, and that their teachers take them seriously. All of this is crucial to motivate students and increases their eagerness and passion to continue their education.

Present study results were confirmed by Bakhshialiabad et al. (2015), ${ }^{[20]} \operatorname{Mohd}(2009),{ }^{[37]}$ and Rahayo (2006) ${ }^{[38]}$ as they found the total DREEM score for their participant nursing students indicated more positive than negative. While Roff $(2005)^{[39]}$ found that the overall DREEM score for studentcentered curricula was higher than for conventional curricula.

The present study findings showed that there were a high statistical significant correlation between senior nursing students' perception of learning environment and their responses to stress, and there were a high statistical significant negative correlation between their perception of learning environment and their coping strategies at $p<.001$. These results are logic where they experienced high levels of stress in clinical practice, and they were unable to use appropriate coping strategies to deal with stress, therefore their responses to stress showed poor health status. Furthermore around half of senior nursing students home-faculty distance take between 30-60 mints and study less than 2 hours/day on the other hand around one third of them sleep less than 5 hours/day that increase the students' burden and stress.

Our results clarified that there was a statistical high significant difference between students enrolled in community course and students enrolled in psychiatric nursing and nursing administration courses total responses to stress and total perception of learning environment at $p<.01$. Also community nursing students experienced higher levels of stress than of psychiatric nursing and nursing administration courses. And that community nursing students experienced poor health status than psychiatric nursing group. This can be justified as during the semester our senior nursing students were divided into two groups the first study psychiatric nursing and nursing administration, while the second group study community nursing specialty, and these groups reversed during the second semester; as a strategy to decrease teacher/student ratio. The students enrolled in nursing administration and psychiatric nursing courses study topics such as problem solving, time management, conflict management, as well as stress management, and effective communication, which may explain the significant difference between the two groups.

\section{Conclusion}

Senior nursing students experienced high levels of stress in clinical practice especially regarding assignment and work load and teachers and nursing staff. Senior nursing students' 134 responses to stress were indicating poor health status. Majority of them sometimes and always use problem focused disengagement and emotional focused disengagement strategies to deal with stress in clinical practice. Senior nursing students' perception of learning environment indicated a more positive than negative environment. This in turn revealed the need to exert extra effort to improve the quality of learning environment and to decrease students' stress.

\subsection{Recommendations for future research on peer eval- uation}

Further research need to examine stressors and coping strategies among nursing students enrolled in all clinical courses. Based on our findings we recommend:

- Nursing schools' administrators need to promote healthy supportive clinical learning environment. Refine the nursing curricula and focus on providing students with skills such as effective communication, innovative problem solving, conflict resolution, time management, and stress management. Also they need to develop training program to enhance clinical teachers' abilities to detect students' stressors and how to manage it to help them enjoy their learning time. Generate strategies to prevent recurrence of stress among nursing students and improve their academic achievement. And generate innovative practices including social support, positive reappraisal, and engagement in leisure pursuits that can reduce student stress.

- Faculty members and clinical instructors need to spend more time with students to build a rapport-based relationship and to understand students' personalities to recognize stress leading areas and set strategies to decrease it.

- Healthcare employers need to implement stress management interventions for both student and qualified nurses.

\subsection{Limitations}

Our study was conducted on the fourth year students, and only so the results cannot be generalized to other nursing student groups.

\section{ACKNOWLEDGEMENTS}

The researchers would like to thank College Dean and Head of Nursing Administration, Community Nursing and Psychiatric Nursing Departments as they gave us the opportunity to complete the project. We also gratefully thank all the nursing students participated in this research.

\section{CONFlicts OF INTEREST Disclosure}

The authors declare that there is no conflict of interest. 


\section{REFERENCES}

[1] Obied H, Abo Gad R. Applying Self-directed Learning Strategy to Enhance Nursing Students' Critical Thinking Skills. IOSR-JNHS. 2017; 6(1): 1-11. https://doi.org/10.9790/1959-0602056777

[2] Jimenez J, Laguna S, Jmenez-Linde I. Coping and health in novice and experienced nursing students during clinical practice: a descriptive, differential and correlational analysis . Journal of Nursing Education and Practice. 2013; 3(11): 152-164. https ://doi .org/10 .5430/jnep.v3n11p152

[3] Nelwati, McKenna L, Plummer V. Indonesian student nurses' perceptions of stress in clinical learning: A phenomenological study. Journal of Nursing Education and Practice. 2013; 3(5): 56-65. http://dx.doi.org/10.5430/jnep.v3n5p56

[4] Pulido-Martos M, Augusto-Landa JM, Lopez-Zafra E. Sources of stress in nursing students: a systematic review of quantitative studies. International Nursing Review. 2012; 59: 15-25. https: //doi.org/10.1111/j.1466-7657.2011.00939.x

[5] Lamk AL. Stress in the Medical Profession and its roots in Medical School. SQU Med J. 2010; 10: 156-9.

[6] Galbraith ND, Brown KE. Assessing intervention effectiveness for reducing stress in student nurses: quantitative systematic review. Journal of Advanced Nursing. 2011; 67(4): 709-721. https : //doi.org/10.1111/j.1365-2648.2010.05549.x

[7] Labrague LJ. Stress, stressors, and stress responses of student nurses in a government nursing school. Health Science Journal. 2013; 7(4): 424-35.

[8] Lazarus RS, Folkman S. Stress, Appraisal and Coping. New York: Springer; 1984.

[9] Sheu S, Lin HS, Hwang SL. Perceived stress and physio-psychosocial status of nursing students during their initial period of clinical practice: The effect of coping behaviours. Int J Nurs Stud. 2002; 39(2): 165-175. https://doi.org/10.1016/S0020-748 9 (01) 00016-5

[10] Shipton SP. The process of seeking stress-care: Coping as experienced by senior baccalaureate nursing students in response to appraised clinical stress. J Nurs Educ. 2000; 41(6): 243-255. PMid:12096773

[11] Hashim IHM. Stress, coping and social supports in the adolescent years. Kajian Malaysian. 2007; 25: 97-115.

[12] Mohamed N, Abd El-Hafez N. Assessment of critical care nursing students' stressors and Coping Strategies During Clinical practice in intensive care and emergency units. Al-Azhar Assiut Medical Journal. 2015; 13(4): 39-50.

[13] Lim Y, Tam C, Lee T. Perceived Stress, Coping Strategy and General Health: a Study on Accounting Students in Malaysia. Journal of Arts, Science \& Commerce. 2013; IV(1): 88-95.

[14] Latif RA, Mat Nor MZ. Stressors and Coping Strategies during Clinical Practices among Diploma Nursing Students, Education in Medicine Journal. 2016; 8(3): 21-33. https://doi .org/10.595 9/eimj.v8i3.422

[15] Khater WA, Zaheya LAZ, Shaban IA. Sources of Stress and Coping Behaviors in Clinical Practice among Baccalaureate Nursing Students. International Journal of Humanities and Social Science. 2014; 4(6): 194-202

[16] Alzayyat A, Almaraira OA, Al-helih YM. Stress and Coping Among Nursing Students During Their Practical Education in Psychiatric Settings: A Literature Review. Journal of Medicine and Medical Science. 2015; 4(5): 240-47.

[17] Hassanein SH, Elshair IH, Abdrbo AA, et al. Coping strategies as predictors of coursework stress among university nursing students. Journal of Nursing Education and Practice. 2017; 7(2): 99-106. http://dx.doi.org/10.5430/jnep.v7n2p99

Published by Sciedu Press
[18] Tobin D, Holrody K, Reynolds R. The hierarchical structure of coping. Paper presented at the meeting of the society of Behavioral Medicine. New Orleans. 1985.

[19] Moscaritolo L. Interventional Strategies to Decrease Nursing Student Anxiety in the Clinical Learning Environment. Journal of Nursing Education. 2009; 48(1): 17-23. PMid:19227751 https : //doi.org/10.3928/01484834-20090101-08

[20] Bakhshialiabad H, Bakhshi M, Hassanshahi G. Students' perceptions of the academic learning environment in seven medical sciences courses based on DREEM. Advances in Medical Education and Practice. 2015; 6: 195-203. PMid:25848331 https://doi.org/10.2 147/AMEP . S60570

[21] Brown T. Williams B, Lynch M. The Australian DREEM: evaluating student perceptions of academic learning environments within eight health science courses. International Journal of Medical Education 2011; 2: 94-101. https://doi.org/10.5116/ijme.4e66.1b37

[22] McAleer S, Roff S. A practical guide to using the Dundee Ready Education Environment Measure (DREEM). AMEE Medical Education Guide. 2001; 23: 29-33.

[23] Eswi AS, Radi S, Youssri H. Stress/stressors as perceived by baccalaureate Saudi nursing students. Middle East J. Sci. Res. Middle East Journal of Scientific Research. 2013; 14(2): 193-202.

[24] Chan KL, So KW, Fong YT. Hong Kong baccalaureate nursing students' stress and their coping strategies in clinical practice. Journal of Professional Nursing. 2009; 25(5): 307-313. https://doi.or g/10.1016/j.profnurs . 2009.01.018

[25] Seyedfatemi N, Tafreshi M, Hagani H. Experienced stressors and coping strategies among Iranian nursing students. BMC Nursing. 2007; 6(1): 11. https ://doi.org/10.1186/1472-6955-6-11

[26] Tully A. Stress, Sources of stress and ways of coping among psychiatric nursing students. Journal of Psychiatric and Mental Health Nursing. 2004; 11(1): 43-47. https://doi.org/10.1111/j.13 65-2850.2004.00682.x

[27] Papazisis G, Tsiga E, Papanikolaou N, et al. Psychological distress, anxiety and depression among nursing students in Greece. International Journal of Caring Sciences. 2008; 1(1): 42-46.

[28] Wang H, Yeh M. Stress, Coping, and Psychological Health of Vocational High School Nursing Students Associated With a Competitive Entrance Exam. Journal of Nursing Research. 2005. PMid:15986312 https ://doi.org/10.1097/01.JNR.0000387532.07395.0b

[29] Evans W, Kelly B. Pre-registration diploma student nurse stress and coping measure. Nurse Education Today. 2004; 24(6): 473-482. PMid:15312957 https : //doi.org/10.1016/j.nedt.2004.05 .004

[30] WHO/EHA. Overview coping mechanisms in emergency health. Training programme for Africa. Panafrican Emergency Training Centre. 1999; 3-13 p.

[31] Kumar R. Stress and coping strategies among nursing students. Nurs Midwifery Res J. 2011; 7: 141-51.

[32] Sohail N. Stress and academic performance among medical students Journal of the College of Physicians and Surgeons-Pakistan: JCPSP. 2013; 23(1): 67-71. PMid:23286627

[33] Pryjmachukl S, Richards D. Predicting stress in pre-registration nursing students. British Journal of Health Psychology. 2007; 12: 125 144. PMid:17288670 https://doi.org/10.1348/135910706X 98524

[34] Shaban IA, Khater WA, Akhu-Zehaya LM. Undergraduate nursing students' stress sources and coping behaviours during their initial period of clinical training: A Jordanian perspective, Nurse Education in Practice. 2012; 12(4): 204-209. https : //doi .org/10.1016/j nepr.2012.01.005 
[35] Ni C, Lo D, Liu X, et al. Chinese female nursing students' coping strategies, self-esteem and related factors in different years of school. Journal of Nursing Education and Practice. 2012; 2(4): 33-41. https://doi.org/10.5430/jnep.v2n4p33

[36] Karimollahi M. An investigation of nursing students' experiences in an Iranian psychiatric unit. J. Psychiatric and Mental Health Nurs. 2011; 19(8): 738-745.

[37] Mohd Said N, Rogayah J, Hafizah A. A study of learning environments in the Kulliyyah (faculty) of Nursing, International Islamic University Malaysia. Malays J Med Sci. 2009; 16(4): 15-24.
PMid:22135508

[38] Rahayo GR. Educational Climate at Nursing Study Program Gadjah Mada University as Measured Using DREEM. Artikel. Jurnal Pendidikan Kedokteran dan Profesi Kesehatan Indonesia. 2006; 1(1): 23.

[39] Roff S. The Dundee Ready Education Environment Measure (DREEM)-a generic instrument for measuring students' perceptions of undergraduate health professions curricula. Med Teach. 2005; 27(4): 322-325. PMid:16024414 https://doi .org/10.1080/01 421590500151054 